\title{
Accuracy of ultrasonography in detecting radiolucent soft-tissue foreign bodies
}

\author{
Tahmasebi Morteza, Zareizadeh Hamdollah, Motamedfar Azim \\ Department of Radiology, Golestan Hospital, Jundishapur Medical University, Ahvaz, Iran \\ Correspondence: Dr. Morteza Tahmasebi, Department of Radiology, Golestan Hospital, Golestan Blvd, Ahvaz, Iran. \\ E-mail: tahmasebilmn@yahoo.com
}

\begin{abstract}
Background and Objective: Detection of radiolucent soft-tissue foreign bodies is a challenging problem, which is especially further complicated when retained foreign body is highly suggested by clinicians but radiography is negative. So, blind exploration is sometimes hazardous for patients. The purpose of this study was to determine the accuracy of ultrasonography (USG) in detecting radiolucent soft-tissue foreign bodies in the extremities. Materials and Methods: From November 2011 to January 2012 , patients with clinically suspected radiolucent soft-tissue foreign body and negative radiography were evaluated by USG with a 12-MHz linear array transducer. The patients with positive clinical and USG examination were included in our study and underwent exploration or USG removal. Results: Fifty-one patients underwent foreign body removal under ultrasonography-guided or surgical exploration and 47 patients had foreign body $(31,12,3$, and 1 case had thorn, wood, glass, and plastic, respectively). Ultrasound was positive in 50 patients. USG falsely predicted the presence of foreign body in four cases and was falsely negative in one of the cases. Accuracy, sensitivity, and positive predictive value were determined as $90.2 \%, 97.9 \%$, and $92 \%$, respectively. Conclusions: The real-time high-frequency USG is a highly sensitive and accurate tool for detecting and removing radiolucent foreign bodies which are difficult to be visualized by routine radiography.
\end{abstract}

Key words: Accuracy; foreign body; radiolucent soft tissue; ultrasonography

\section{Introduction}

Penetrating foreign bodies are common in patients visiting emergency departments. ${ }^{[1,2]}$ Due to the vast abundance of palm tree fields in southern Iran, the probability of entrance of palm tree splinters as a radiolucent foreign body in the extremities, especially the sole of the foot, is high. The missed foreign body may remain asymptomatic for prolonged periods or else lead to a wide range of complications including pain, abscess, chronic discharging wound, necrotizing fasciitis, ${ }^{[3,4]}$ bone and joint destructive

\begin{tabular}{|l|l|}
\hline \multicolumn{2}{|c|}{ Access this article online } \\
\hline Quick Response Code: & \\
\hline & Website: \\
\hline
\end{tabular}

lesions, ${ }^{[5]}$ granulomas, ${ }^{[6]}$ with impairment of tendon mobility or triggering of digits, ${ }^{[7]}$ migration, ${ }^{[8]}$ delayed tendon ruptures, ${ }^{[8,9]}$ neurodeficits, ${ }^{[7,10]}$ pyogenic granulomas, ${ }^{[11]}$ and vascular events. ${ }^{[12,13]}$ Errors in preoperative localization may lead to prolonged operational and massive soft-tissue injury. ${ }^{[14]} \mathrm{A}$ missed foreign body is found to be the second leading cause of lawsuits against emergency doctors. ${ }^{[15]}$ Such foreign bodies may remain undetected even after exploration. ${ }^{[16-19]}$ In the literature, depending upon the nature of the foreign body and the available facilities, various modalities of imaging are recommended for diagnosis and localization.

Traditionally, plain radiographs have been the first modality of choice for the diagnosis of foreign bodies. It is well documented that plain radiographs are successful in detecting radiopaque foreign bodies in the soft tissue. ${ }^{[20]}$ However, non-radiopaque foreign bodies in the soft tissue could not be detected in all cases. ${ }^{[21-24]}$ If a non-radiopaque object cannot be visualized on plain radiographs, 
alternative imaging techniques such as USG, computed tomography, and magnetic resonance imaging have been suggested.

\section{Materials and Methods}

From November 2011 to December 2012, patients with clinically suspicious soft-tissue foreign body and negative radiography were referred to a radiologist for a soft-tissue sonographic examination and localization of the foreign body. All the radiographs were reviewed by the radiologist. The patients with positive sonographic examination were referred for surgical exploration or USG-guided removal. USG scans were done in the sagittal, coronal, and axial planes. High-frequency (12 $\mathrm{MHz}$ ) transducer was used for better spatial resolution. After detecting the soft-tissue foreign body by USG, the next step was characterizing the size, location, depth, relationship, and orientation of the foreign body to other structures such as muscle, tendon, bone, and vessels. After that, foreign body removal was carried out by direct USG vision or by surgical exploration.

\section{Statistical analysis}

The overall percent values of accuracy, sensitivity, specificity, positive predictive value (PPV), and negative predictive value (NPV) were derived for each of the patients. The difference between sensitivity and specificity for each patient was tested for significance using McNemar's test of symmetry. The data were analyzed using SPSS 16.0.

\section{Results}

Fifty-one patients underwent foreign body removal under USG-guided removal or surgical exploration. Forty-one patients $(80.4 \%)$ were males and 10 patients $(19.6 \%)$ were females. Mean age of the patients was $24.95 \pm 13.4$ (range $1.5-53$ years). Duration of the patients' complaint was from 1 day to 5 years, while in $50 \%$ of cases, it was less than a month. Predominant chief complaints of the patients were: foreign body sensation in $24(47.1 \%)$, discharging wound in $15(29.4 \%)$, and pain in 12 (23.5\%) cases. Ten cases $(19.5 \%)$ had a history of surgical exploration without the use of USG examination, which had no foreign body detected. On USG scan, $100 \%$ of the foreign bodies were echogenic. Also, 19 (38\%), 16 (32\%), and 14 (28\%) cases had posterior acoustic shadowing (PAS), hypoechoic halo, and collection around a foreign body, respectively. USG revealed a foreign body in 50 patients [Table 1]. All the patients underwent surgical exploration or USG-guided removal, and in 46 patients, a foreign body was successfully removed [Table 2]. One patient with a negative USG examination who was symptomatic and did not respond to medical therapy was explored surgically and a 7-mm thorn was removed. USG was falsely positive in three cases with recent failed surgical manipulation due to the presence of air bubbles and scar tissue, as well in as one case with calcified granuloma.

Foreign bodies were thorn, ${ }^{[25]}$ wood, ${ }^{[12]}$ glass, ${ }^{[3]}$ and plastic ${ }^{[1]}$ [Table 3, Figures 1-3]. The sites of the foreign bodies were foot, ${ }^{[26]}$ hand, ${ }^{[9]}$ leg, ${ }^{[6]}$ arm, ${ }^{[3]}$ forearm, ${ }^{[2]}$ ankle, ${ }^{[2]}$ wrist, ${ }^{[1]}$ knee, ${ }^{[1]}$ and thigh. ${ }^{[1]}$ The size of the foreign body was from 4 to $51 \mathrm{~mm}$, while in $50 \%$ of cases, the size of the foreign body was more than $13 \mathrm{~mm}$.

Table 1: Ultrasonographic results of the patients who were explored for the foreign body

\begin{tabular}{lcc}
\hline & Number & Percent \\
\hline Negative & 1 & 2 \\
Positive & 50 & 98 \\
Total & 51 & 100 \\
\hline
\end{tabular}

Table 2: Surgical results

\begin{tabular}{lcc}
\hline & Number & Percent \\
\hline Negative & 4 & 7.8 \\
Positive & 47 & 92.2 \\
Total & 51 & 100 \\
\hline
\end{tabular}

Table 3: Nature of the foreign body

\begin{tabular}{lc}
\hline Nature & Number $(\%)$ \\
\hline Thorn & $31(60.8)$ \\
Plastic & $1(2)$ \\
Wood & $12(23.5)$ \\
Glass & $3(5.9)$ \\
Calcified granuloma & $1(2)$ \\
\hline
\end{tabular}

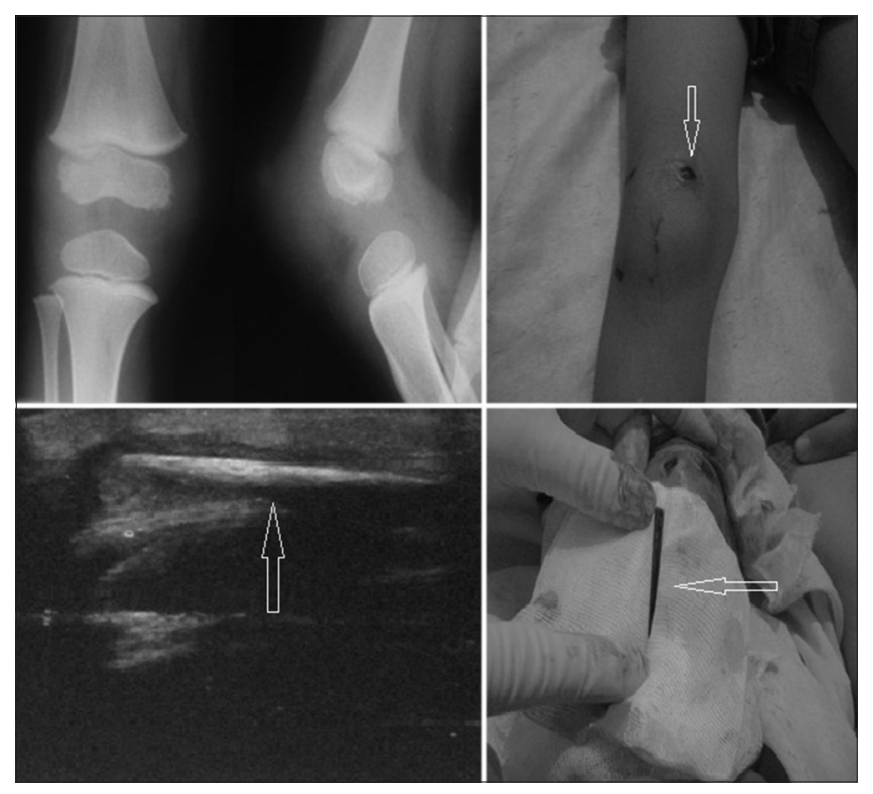

Figure 1: A nine years old boy with discharging wound of right knee. Foreign body is not visible in the radiograph but it appears as an echogenic linear structure (arrow) with hypoechoic halo in USG. Surgical exploration revealed a $38 \mathrm{~mm}$ thorn (arrow) 


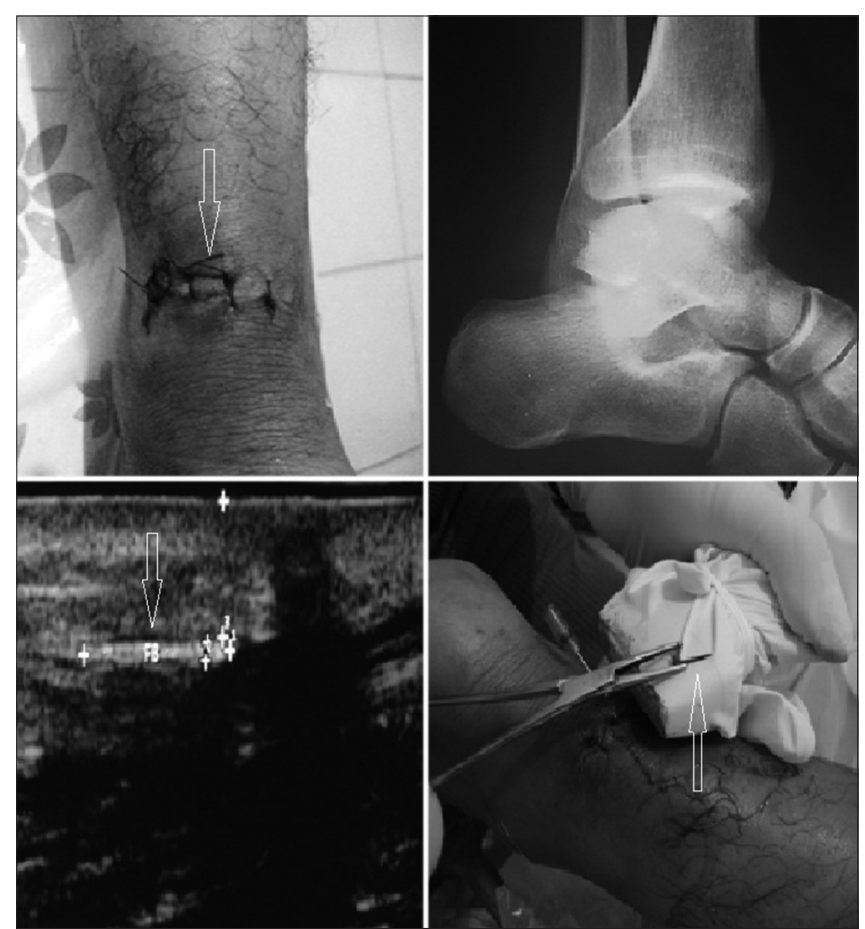

Figure 2: A 32-year-old male with a history of foreign body in the leg and negative radiography and failed surgery (arrow), referred for USG; finally, an echogenic linear structure of $12 \mathrm{~mm}$ in length was detected (arrow) and then a $12 \mathrm{~mm}$ thorn removed under USG guidance (arrow)

The accuracy, sensitivity, and PPV of this study were $90.2 \%$, $97.9 \%$, and $92 \%$, respectively.

\section{Discussion}

Conventional radiographs should be obtained to rule out the presence of radiopaque foreign objects. Radiopaque material is usually easy to detect, but radiolucent bodies like wooden splinters are difficult to detect and usually missed. ${ }^{[26]}$ The missed foreign bodies may produce immediate symptoms like wound infections or may remain asymptomatic for even decades. ${ }^{[27]}$

In this study, all the standard radiographs were negative and this is comparable with the study results of Anderson et al. ${ }^{[27]}$ and Matthew et al. ${ }^{[28]}$ which showed that only $15 \%$ and $7 \%$ of radiolucent foreign bodies appeared in radiographic studies, respectively. This study suggests that USG is a highly sensitive and accurate modality in detecting radiolucent foreign bodies that are difficult to be visualized on standard radiographs.

Chad et al. ${ }^{[29]}$ reported overall sensitivity and PPV of $52.6 \%$ and $79.9 \%$, respectively, for USG in the detection of foreign body. This was a cadaveric study that may not have optimally represented live human tissue. Furthermore, in this study, USG was done by emergency physicians in training; on the contrary, in our study, it was done by an expert radiologist. In Ibrahim Turkcuer et al.' $\mathrm{s}^{[30]}$ study, the

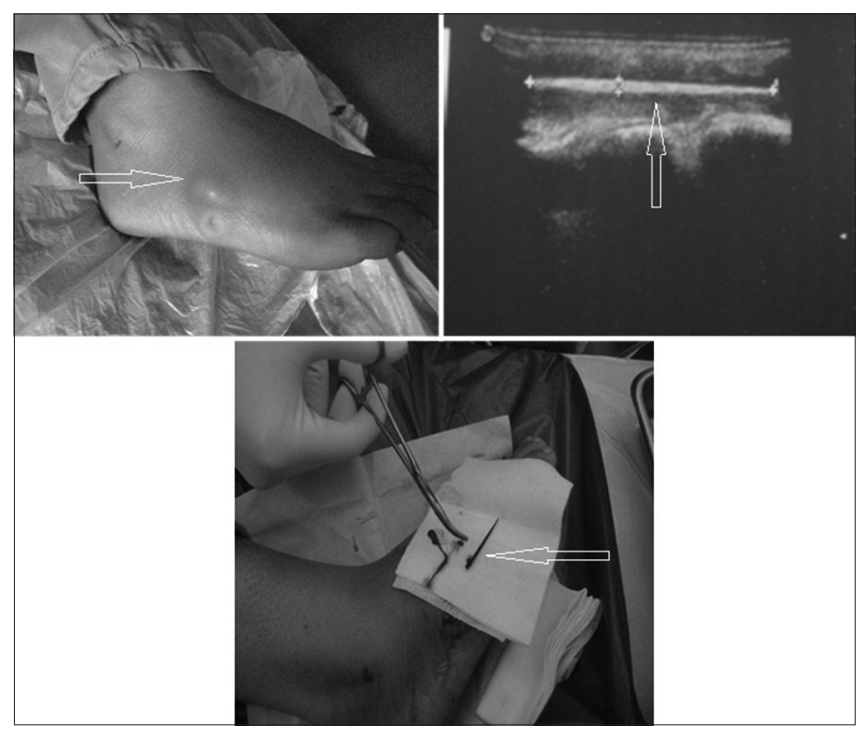

Figure 3: An 18 year old female was referred with focal swelling of right foot since two month ago (arrow); furthermore, USG showed an echogenic linear foreign body (arrow), and surgical exploration revealed a $23 \mathrm{~mm}$ thorn (arrow)

overall sensitivity and PPV of USG in detecting radiolucent foreign body was $90 \%$ and $81 \%$, respectively; however, as compared to our study, this was an in vitro study. Furthermore, it was a classic study with use of same size and shape wood and rubber foreign bodies in chicken thighs as compared to our study with foreign bodies of different size, shape and type in live human cases.

The accuracy, sensitivity, and PPV of USG determined by a radiologist in detecting radiolucent foreign body were $83 \%$, $83 \%$, and $83 \%$ in Michael Orlinsky et al.'s study. ${ }^{[31]}$ Similar to the previous studies, this was a non-human study and they used chicken thighs that are not exactly the same as human tissues.

Our study results are similar to those of Gilbert and Campbell's study ${ }^{[25]}$ that detected foreign bodies by USG in 24 patients ( 21 true positive and 3 false positive). The sensitivity of USG in this study was $95.4 \%$. In our study, the sensitivity was $97.9 \%$. In the Gilbert and Campbell's study, wood was the most common foreign body; however, in our study, thorn was most common.

Compared to other studies, we revealed a higher accuracy and sensitivity for USG in detecting radiolucent foreign bodies. If high-resolution USG is available, we recommend it as the first imaging modality for evaluating the patients with clinically suspicious radiolucent foreign body because of its availability, high sensitivity, and absence of radiation. In patients with history of soft tissue foreign body and negative radiography, we recommend USG as the most important diagnostic tool before discharging patients. USG gives important information about the size, depth, and relationship of foreign bodies to other structures such as 
vessels and tendons and makes exploration easier for the surgeon. ${ }^{[2]}$ Furthermore, an important advantage of USG is the possibility of real-time guided removal of foreign body under sterile condition, and due to its safety and less complication rate, it may replace surgical exploration.

In this regard, USG was not only used as a diagnostic modality for detecting foreign bodies, but also in more than $30(58.8 \%)$ cases, a foreign body was removed by USG-guidance without short or long-term complication. In our study, USG-guided removal of foreign body prevented extensive dissection in comparison to surgical exploration. Furthermore, the size and depth of the incision were decreased by USG-guided removal and the patient's comfort level was excellent.

In this study, one of the cases was missed by sonographic evaluation because of vertical orientation of the foreign body near the knee joint, which made it impossible to detect the length of foreign body in the axial and sagittal scan. In this circumstance, if scanning in the coronal or oblique planes was done precisely, it may be revealed. So, a combination of axial, sagittal and coronal scans, if needed, oblique scans are recommended for identifying soft-tissue foreign bodies and to avoid missing them in highly suspicious cases.

Also, USG was falsely positive in four cases. Three of them had history of previous failed surgical exploration. Air introduced in the soft tissue by surgical exploration, as well as scar tissue due to the exploration mimicked the foreign body and they were the causes of false-positive results. So, in the cases with history of soft-tissue manipulation before sonographic examination, the accuracy and sensitivity of USG seems to be decreased, and in this situation, care must be taken to avoid pitfalls.

Real-time high-frequency USG is a highly sensitive and accurate tool for detecting and removing the radiolucent foreign bodies, which are difficult to be visualized by routine radiography.

\section{Acknowledgment}

Special thanks to Golestan Hospital Clinical Research Development Unit for editing and submission consultation. This paper is issued from thesis of Hamdollah Zareizadeh.

\section{References}

1. Boyse TD, Fessell DP, Jacobson JA, Lin J, van Holsbeeck MT, Hayes CW. US of soft-tissue foreign bodies and associated complications with surgical correlation. Radiographics 2001;21:1251-6.

2. Saki N, Nikakhlagh S, Rahim F, Abshirini H. Foreign body aspirations in infancy: A 20-year experience. Int J Med Sci 2009;6:322-8.

3. Borgohain B, Borgohain N, Nandique A, Gogoi PJ. Case report and brief review of literature on sonographic detection of accidentally implanted wooden foreign body causing persistent sinus. Crit Ultrasound J 2012;4:10.

4. Yanay O, Vaughan DJ, Diab M, Brownstein D, Brogan TV. Retained wooden foreign body in a child's thigh complicated by severe necrotizing fasciitis: A case report and discussion of imaging modalities for early diagnosis. Pediatr Emerg Care 2001;17:354-5.

5. Fakoor M. Prolonged retention of an intra-medullary wooden foreign body. Pak J Med Sci 2006;22:78-9.

6. Freund EI, Weigl K. Foreign body granuloma. A cause of trigger thumb. J Hand Surg Br 1984;9:210.

7. Choudhari KA, Muthu T, Tan MH. Progressive ulnar neuropathy caused by delayed migration of a foreign body. Br J Neurosurg 2001;15:263-5.

8. Yang SS, Bear BJ, Wieland AJ. Rupture of the flexor pollicislongus tendon after 30 years due to migration of a retained foreign body. J Hand Surg Br 1995;20:803-5.

9. Jablon M, Rabin SI. Late flexor pollicislongus tendon rupture due to retained glass fragments. J Hand Surg Am 1988;13:713-6.

10. Rainer C, Schoeller T, Wechselberger G, Bauer T, Hussl H. Median nerve injury caused by missed foreign body. Scand J Plast Reconstr Surg Hand Surg 2000;34:401-3.

11. Azzopardi EA, Xuereb CB, Iyer S. Pyogenic granuloma as a surrogate indicator of deep seated foreign bodies: A case report. Cases J 2009;2:7354.

12. James W, Robert A, Suzanne M. Vascular complications of a foreign body in the hand of an asymptomatic patient. Ann Plast Surg 1995;34:92-4.

13. Meurer WJ. Radial artery pseudo aneurysm caused by occult retained glass from a hand laceration. Pediatr Emerg Care 2009;25:255-7.

14. Coombs CJ, Mutimer KL, Slattery PG, Wise AG. Hide and seek: Pre-operative ultrasound localization of non-radio-opaque foreign bodies. Aust N Z J Surg 1990;60:989-91.

15. Dunn JD. Risk management in emergency medicine. Emerg Med Clin North Am 1987;5:51-69.

16. Anderson MA, Newmeyer WL $3^{\text {rd }}$, Kilgore ES Jr. Diagnosis and treatment of retained foreign bodies in the hand. Am J Surg 1982;144:63-7.

17. Combs AH, Kernek CB, Heck DA. Retained wooden foreign body in the foot detected by computed tomography. Orthopedics 1986;9:143-5.

18. Cracchiolo A. Wooden foreign bodies in the foot. Am J Surg 1980;140:585-7.

19. Fornage BD, Schernberg FL, Rifkin MD. Ultrasound examination of the hand. Radiology 1985;155:785-8.

20. Flom LL, Ellis GL. Radiologic evaluation of foreign bodies. Emerg Med Clin North Am 1992;10:163-77.

21. Kjhns LR, Borlaza GS, Seigel RS, Paramagul C, Berger PE. An in vitro comparison of computed tomography, xerography, and radiography in the detection of soft-tissue foreign bodies. Radiology 1979;132:218-9.

22. Bodne D, Quinn SF, Cochran CF. Imaging foreign glass and wooden bodies of the extremities with CT and MR. J Comput Assist Tomogr 1988;12:608-11.

23. Graham DD Jr. Ultrasound in the emergency department: Detection of wooden foreign bodies in the soft tissues. J Emerg Med 2002;22:75-9.

24. Venter NG, Jamel N, Marques RG, Djahjah F, Mendonça Lde S. Evaluation of radiological methods for detection of wood foreign body in animal model. Acta Cir Bras 2005;20:19-26.

25. Gilbert FJ, Campbell RSD, Bayliss AP. The role of ultrasound 
in the detection of non-radiopaque foreign bodies. Clin Radiol 1990;41:109-12.

26. Vukmir RB. Medical malpractice: Managing the risk. Med Law 2004;23:495-513.

27. Anderson MA, Newmeyer WL, Kilgore ES Jr. Diagnosis and treatment of retained foreign bodies in the hand. Am J Surg 1982;144:63-7.

28. Levine MR, Gorman SM, Young CF, Courtney DM. Clinical characteristics and management of wound foreign bodies in the ED. Am J Emerg Med 2008;26:918-22.

29. Crystal CS, Masneri DA, Hellums JS, Kaylor DW, Young SE, Miller MA, et al. Bedside ultrasound for the detection of soft tissue foreign bodies: A cadaveric study. J Emerg Med 2009;36:377-80.
30. Turkcuer I, Atilla R, Topacoglu H, Yanturali S, Kiyan S, Kabakci N, et al. Do we really need plain and soft- tissue radiographies to detect radiolucent foreign bodies in the ED. Am J Emerg Med 2006;24:763-8.

31. Orlinsky M, Knittel P, Feit T, Chan L, Mandavia D. The comparative accuracy of radiolucent foreign body detection using ultra sonography. Am J Emerg Med 2000;18:401-3.

Cite this article as: Tahmasebi $\mathrm{M}$, Zareizadeh $\mathrm{H}$, Motamedfar $\mathrm{A}$. Accuracy of ultrasonography in detecting radiolucent soft-tissue foreign bodies. Indian J Radiol Imaging 2014;24:196-200.

Source of Support: Nil, Conflict of Interest: None declared. 